\title{
Out of the Smokescreen: does an anti-smoking advertisement affect young women's perception of smoking in movies and their intention to smoke?
}

\author{
C A Edwards, W C Harris, D R Cook, K F Bedford, Y Zuo
}

Tobacco Control 2004;13:277-282. doi: 10.1136/tc.2003.005280

See end of article for authors' affiliations

\section{Correspondence to:} Ms Christine A Edwards, Health Promotion, Central Coast Health, PO Box 361, Gosford 2250, NSW Australia; cedwards@doh. health.nsw.gov.au

Received 27 July 2003 Accepted 31 March 2004
Objective: To evaluate the effect of an anti-smoking advertisement on young women's perceptions of smoking in movies and their intention to smoke.

Subjects/setting: 2038 females aged 12-17 years attending cinemas in New South Wales, Australia. Design/intervention: Quasi-experimental study of patrons, who were surveyed after having viewed a movie at their local cinema. The control group was surveyed during week 1 and the intervention group, during week 2. Before seeing the movie in week 2, a 30 second anti-smoking advertisement was shown, which featured a well known female actor drawing attention to the prevalence of smoking in movies.

Outcomes: Attitude of current smokers and non-smokers to smoking in the movies; intention of current smokers and non-smokers to be smoking in 12 months time.

Results: Among non-smokers, $48.2 \%$ of the intervention subjects thought that the smoking in the movie they viewed was "not OK" compared with $28.3 \%$ of the control subjects ( $p<0.0001)$. However, there was no difference among smokers in the intervention $(26.4 \%)$ and control $(16.9 \%)$ groups $(p=0.28)$. A higher percentage of current smokers in the intervention group indicated they were unlikely to smoke in 12 months time (47.8\%) than smokers in the control condition (31.9\%) $(p=0.03)$. For non-smokers, there was no difference in smoking intentions between conditions, with $95 \%$ saying they would be unlikely to be smoking in 12 months time.

Conclusions: This "real world" study suggests that placing an anti-smoking advertisement before movies containing smoking scenes can help to "immunise" young women against the influences of film stars smoking.
$\mathrm{T}$ hroughout the last decade, tobacco companies have devised increasingly innovative and aggressive strategies for attracting potential consumers. ${ }^{12}$ One of the most sought after groups of new smokers is young women, particularly those in the 12-17 year age bracket. ${ }^{3}$ The use of product placement in films popular with young women is a strategy that has been the focus of comment and criticism by numerous international health and anti-smoking lobby groups. $^{4}$

Sargent et al $2001^{5}$ documented an overall increase in the depiction of smoking in films in the 1990s that appeared to coincide directly with restrictions in advertising. ${ }^{6}$ The lead actors and actresses who smoke are often likeable, rebellious, attractive, and/or successful. ${ }^{7}$ Role models bearing such characteristics are often used in direct tobacco advertising. ${ }^{8}$ Escamilla et $a l^{9}$ analysed the portrayal of smoking in Hollywood films and found that smoking is highly prevalent in films featuring popular actresses and leading female actors were as likely to smoke in movies aimed at juvenile audiences as in $\mathrm{R}$ rated movies. McIntosh et al ${ }^{10}$ compared Hollywood's depiction of smokers to real-world demographics on smoking and found that smoking as it appears in movies tends to ignore the negative consequences and correlates of smoking, a finding confirmed by Dalton et al. ${ }^{11}$

There is mounting evidence linking Hollywood's depiction of smoking in movies and adolescents attitudes to smoking and their smoking behaviour. Tickle et al ${ }^{12}$ showed that adolescents whose favourite movie stars use tobacco onscreen are significantly more likely to be at a more advanced stage of smoking uptake and to have more favourable attitudes towards smoking than adolescents who choose non-smoking stars. Studies by Sargent et al $^{13}$ and Distefan et al $^{14}$ provide even stronger evidence that viewing smoking in movies promotes smoking initiation among adolescents. A cohort study by Dalton et al ${ }^{15}$ suggests that viewing smoking in movies strongly predicts whether or not adolescents initiate smoking and the effect increases significantly with greater exposure.

The majority of young people, including those of varied cultural background, attend the cinema on a regular basis. ${ }^{16}{ }^{17}$ A significant advantage in using this medium for an antismoking campaign is the potential to reach a large number of young women in a cost effective manner. ${ }^{18}$ A 1996 Western Australian Quit campaign using cinema advertising showed good unprompted and prompted recall of the advertisement and the main message of an anti-smoking campaign. ${ }^{19}$

A study by Pechmann $1999^{18}$ suggested that young people can be "immunised" against the influences of film stars smoking by showing a strong anti-smoking advertisement before those films that contain smoking scenes. Pechmann's findings support the psychological Theory of Reasoned Action, ${ }^{20} 21$ which states that the strength of a person's intention to behave in a certain way is a function of attitudes toward the behaviour and the influence of general subjective norms on the behaviour. The model assumes that behavourial intention is the immediate determinant of behaviour. According to this theory an anti-smoking advertisement may alter the positive attitudes towards smoking that are portrayed in movies and elicit more realistic normative perceptions of the practice of smoking. This should theoretically alter the viewers' intention to smoke and subsequently reduce their likelihood of smoking in the future. The Elaboration Likelihood Model of Persuasion ${ }^{22}$ suggests that attitude change can be either via the central route, which 
utilises deliberate information processing to assess an issue, or via the peripheral route, which takes less effort and may even be subliminal. Smoking scenes in movies influence young people via the peripheral route. An anti-smoking ad attempts to change attitudes through the central route which, according to the theory, is more enduring and more likely to lead to long term behaviour change.

This paper evaluates the use of this approach in an intervention conducted in a real world cinema setting in New South Wales (NSW), Australia. The objective of the study was to evaluate the effect of an anti-smoking advertisement on young women's perceptions of smoking in movies and their intention to smoke. It was hypothesised that, when an anti-smoking advertisement is shown before a movie containing smoking scenes, viewers will be (a) less likely to perceive the smoking as justified and (b) less likely to report an intention to smoke in the future.

\section{METHODS Study design}

This quasi-experimental controlled study of female adolescents was conducted in cinemas in Central Sydney (metropolitan), Central Coast (regional), and Macquarie (rural) during a two week period over the NSW July 2002 school holidays. Adolescents were surveyed upon leaving the movie. Given the setting of this study in the "real world", it was not possible to randomly allocate patrons to control and intervention groups. The movies seen by the intervention and control groups were identical. The control group was surveyed during week 1 , and the experimental group during week 2 . A 30 second anti-smoking advertisement was shown before seeing the movie in week 2 .

\section{Subjects}

Of the 2205 females approached who appeared to be aged between 12 and 17 years, 2038 completed questionnaires and 167 refused, providing a response rate of $92.4 \%$. Most refusals gave "in a hurry" or "couldn't be bothered" as reasons for not wanting to complete the questionnaire. Central Sydney (metropolitan) contributed $28.5 \%$ of the total sample, Central Coast (regional) contributed 51.4\%, and Macquarie (rural) contributed $20.2 \%$ of the sample.

\section{Materials}

\section{Anti-smoking advertisement}

The Australian National Tobacco Campaign (NTC) was launched in 1997 and aimed primarily to assist smokers aged 18-40 years to quit smoking. As a mass media led campaign, the NTC is the longest and most intense antitobacco campaign ever seen nationally in Australia. ${ }^{23} \mathrm{~A}$ survey of 400 teenagers was conducted in 1998 to assess the impact of the NTC "Every cigarette is doing you damage" on teenagers aged 14-17 years. Although the campaign was not targeted at teenagers, the results showed recognition of the campaign by $96 \%$ of teenage smokers and recent quitters; $85 \%$ of smokers and recent quitters found the campaign relevant to them; more teenagers than adults reported new learning about the health effects of smoking and said the campaign advertising made them more likely to quit; $86 \%$ of non-smoking teenagers said the campaign helped them to remain non-smokers; and $80 \%$ of teenagers said the campaign made smoking seem less cool and desirable. ${ }^{24}$

To facilitate the current study, the NTC gave approval to allow use of their "Tar" advertisement in cinemas with a new voice-over containing the message we wished to convey. The "Tar" advertisement, featuring a young female smoker, aims to highlight and reinforce the fact that every cigarette delivers tar into smokers' lungs. It graphically demonstrates the damage that smoking does to the body by pouring a beaker of tar ("the amount of tar a pack-a-day smoker inhales") over a lung. The original voice-over, spoken by an authoritative male voice was removed, except for the final campaign slogan "every cigarette is doing you damage".

It was hypothesised that the best option to present the new voice-over message, designed to alter the adolescents' perceptions of their favourite actors smoking, would be a favourite actor. After consulting research showing that females performed better in identification with words read by a female voice, ${ }^{25}{ }^{26}$ it was decided to select a female actor for the voice-over. To ensure the use of an appropriate and influential female voice-over an ad hoc survey of 175 teenage girls between 12 and 17 years was conducted outside local shopping centres. A list of women, appearing on Australian television or in movies popular with the target group, was then provided for the participants to rank in order from 1 (most likely) to 6 (least likely). The survey results clearly indicated that Tammin Surszock (a high profile Australian teenage "soap" star) was the target group's choice to use as a voice-over to deliver the following anti-smoking message:

\section{"Hi, I'm Tammin Surszock. I play Danni in "Home and Away". You've seen this ad on TV - it's pretty gross, isn't it? I don't smoke and most actors I know don't smoke in real life. So it makes you wonder why there's so much smoking in movies. Next time you see someone smoking in a movie, just remember EVERY CIGARETTE IS DOING YOU DAMAGE."}

There were some concerns about "muddying" the message by having the female voice-over talking about smoking in movies while an advertisement showing the health consequences of smoking was running in the background. Three focus groups were conducted with 24 young women, 12-17 years old, using a mock up of the proposed commercial with the female voice-over, and asked respondents what they thought the message was. The female voice-over provided a new perspective that did not interfere with their understanding of the original message.

\begin{abstract}
Movies
"Screenit", an internet film review site providing content information about films, ${ }^{27}$ was used to identify movies due for upcoming release in Australia that would appeal to young women and depicted smoking. In the review, scenes where characters smoke are noted. If the movie is full of such scenes, it is rated "extreme" smoking, if there are many smoking scenes it is rated "heavy" smoking, more than occasional smoking is rated "moderate", and many incidents of smoking rather than full scenes is rated as "mild" smoking in the movie. Relevant movies were selected for the study, based on overseas trends of attendance of females aged 12-17 years. Five different movies containing varying amounts of smoking were used.
\end{abstract}

\section{Questionnaire}

The questionnaire was based loosely on questions asked in Pechmann and Shih's 1999 study, ${ }^{18}$ but was much shorter given that it was administered as young people left the cinema and not in a classroom context. The one page questionnaire asked respondents what movie they had seen, whether there was any smoking in the movie, and if "yes" which characters smoked. They were then asked "was it OK the character/s were smoking?" A five point Likert scale was provided. Respondents could choose from "definitely not OK", "somewhat not OK", "no opinion", "somewhat OK", and "definitely OK". Responses were subsequently recoded into "not OK", "no opinion", and "OK". This was necessary 
Table 1 Characteristics of intervention and control groups

\begin{tabular}{|c|c|c|c|c|c|}
\hline & \multicolumn{2}{|l|}{ Control } & \multicolumn{2}{|c|}{ Intervention } & \multirow[b]{2}{*}{ p Value } \\
\hline & $n=804$ & $\%$ & $n=1234$ & $\%$ & \\
\hline Current smokers* & 73 & 9.1 & 113 & 9.2 & 0.95 \\
\hline \multicolumn{6}{|l|}{ Age } \\
\hline 12 year olds & 159 & 19.8 & 296 & 24.0 & 0.07 \\
\hline 13 year olds & 179 & 22.3 & 283 & 22.9 & 0.78 \\
\hline 14 year olds & 152 & 18.9 & 283 & 22.9 & 0.08 \\
\hline 15 year olds & 107 & 13.3 & 176 & 14.3 & 0.6 \\
\hline 16 year olds $†$ & 114 & 14.2 & 114 & 9.2 & 0.002 \\
\hline 17 year olds $\uparrow$ & 93 & 11.6 & 82 & 6.7 & 0.0004 \\
\hline \multicolumn{6}{|l|}{ Movie } \\
\hline Divine Secrets of the Ya Ya Sisterhood & 8 & 1.0 & 19 & 1.5 & 0.3 \\
\hline Birthday Girl & 20 & 2.5 & 37 & 3.0 & 0.51 \\
\hline About A Boy† & 5 & 0.6 & 28 & 2.3 & 0.005 \\
\hline Mr Deeds & 146 & 18.2 & 190 & 15.4 & 0.17 \\
\hline Men in Black II & 625 & 77.7 & 960 & 77.8 & 0.99 \\
\hline
\end{tabular}

because the small percentage of smokers in the sample meant that the sample was too small to analyse using all five responses.

Respondents were also asked "have you smoked cigarettes in the last 4 weeks?" and "do you think you will be smoking cigarettes this time next year?" A 7 point Likert scale was provided that included "certain not to be smoking", "very unlikely to be smoking", "unlikely to be smoking", "can't decide how likely", "likely to be smoking", "very likely to be smoking", and "certain to be smoking". Responses were subsequently recoded into "likely to be smoking", "can't decide how likely", and "unlikely to be smoking".

Those respondents who were part of the intervention group were asked what the health advertisement screened before the movie was about. This was a multiple choice question that included "alcohol abuse", "sniffing glue", "gang violence", "teenage pregnancy", "anti-smoking", and "I don't know".

\section{Procedure}

As young female patrons were about to enter their chosen movie, they were given a flyer informing them that they would receive a free lipgloss if they completed a short pen and paper questionnaire after viewing the movie. After screening of the target movies, all female audience members who appeared to be aged 12-17 years were approached as they left the cinema. After their age was confirmed, they were invited to complete the questionnaire.

\section{Statistical analysis}

$\chi^{2}$ tests were used to assess whether the characteristics of subjects in the intervention and control conditions were comparable. $\chi^{2}$ tests were also used to compare the intervention and control groups with respect to recognition of smoking in the movie, approval of the smoking in the movie, and intention to smoke in the future. Binomial logistic regression was used to compare the intervention and control groups with respect to approval of smoking in the movie and intention to smoke, while adjusting for variables that were not evenly distributed across conditions.

\section{RESULTS}

\section{Characteristics of patrons}

Of the total sample of 2038 females, 1234 (39.5\%) completed the intervention questionnaire after seeing one of several targeted movies with the anti-smoking advertisement screened before the start of the movie. Eight hundred and four young women $(60.5 \%)$ completed the control questionnaire after seeing one of the targeted movies without the anti-smoking advertisement attached. Respondents had a mean (SD) age of 13.9 (1.58) years and a median of 14 years. Only $9.2 \%$ reported had smoked cigarettes in the previous four weeks. Table l compares the characteristics of the intervention and control groups, finding no differences except in relation to age and exposure to particular movies. Overall, 16 and 17 year olds were not evenly distributed between control and intervention groups. Subjects who saw the movie "About a Boy" were also not evenly distributed between conditions.

\section{Recall of the advertisement}

Subjects were asked if they recalled seeing a health advertisement immediately before the movie and, if so, what type of advertisement (multiple choice). Most subjects in the

Table 2 Recall of anti-smoking advertisement as a function of the level of on-screen smoking in the target movie

\begin{tabular}{|c|c|c|}
\hline Movie & Level of smoking & $\begin{array}{l}\% \text { recalled advertisement } \\
n=1234\end{array}$ \\
\hline $\begin{array}{l}\text { Divine Secrets of the Ya Ya Sisterhood } \\
\text { Birthday Girl }^{29} \\
\text { About A Boy }^{30} \\
\text { Mr Deeds } \\
{ }^{3} \text { Men in Black } \|^{32} \\
\text { Total }\end{array}$ & $\begin{array}{l}\text { Moderate } \\
\text { Heavy } \\
\text { Mild } \\
\text { Mild } \\
\text { Mild }\end{array}$ & $\begin{array}{l}89.5 \\
75.7 \\
71.4 \\
60.0 \\
56.5^{*} \\
58.4\end{array}$ \\
\hline \multicolumn{3}{|c|}{$\begin{array}{l}\text { *Men in Black II had a competing alcohol advertisement screening before the movie in two of the three areas } \\
\text { unbeknown beforehand to the researchers. The recall rate for Men in Black II in the area with no competing } \\
\text { advertisement was } 68.1 \% \text {. }\end{array}$} \\
\hline
\end{tabular}


Table 3 Approval of smoking in the movie for smokers and non-smokers, by condition

\begin{tabular}{llllll}
\hline & \multicolumn{2}{l}{ Non-smokers } & & \multicolumn{2}{l}{ Smokers } \\
\cline { 2 - 3 } \cline { 5 - 6 } & Control $\mathbf{n = 7 1 6}$ & Intervention $\mathbf{n = 1 0 8 2}$ & & Control $\mathbf{n = 7 1}$ & Intervention $\mathbf{n = 1 1 0}$ \\
\hline "Not OK" & $28.3 \%$ & $48.2 \%$ & $16.9 \%$ & $26.4 \%$ \\
No opinion & $29.6 \%$ & $26.5 \%$ & $31.0 \%$ & $30.9 \%$ \\
"OK" & $42.2 \%$ & $25.2 \%$ & $52.1 \%$ & $42.7 \%$ \\
\hline
\end{tabular}

intervention group $(58.4 \%)$ could recall seeing an antismoking advertisement when surveyed immediately after the movie. Table 2 shows that recall of the anti-smoking advertisement was greatest among subjects who saw movies depicting moderate to heavy on-screen smoking, compared with subjects who saw movies with mild levels of on-screen smoking $\left(\chi^{2}=11.61, \mathrm{df}=2, \mathrm{p}=0.0007\right)$.

\section{Recall of smoking in the movie}

Eighty three per cent of both control and intervention subjects recalled characters smoking in the movie. All of the $83 \%$ who recalled the smoking could correctly name (or describe) at least one character who was smoking in the movie without being prompted. Two subjects incorrectly identified characters who were not smoking. Recall of a character smoking in the movie was significantly related to the level of smoking in the movie, with $100 \%$ recalling a smoking character in movies with a "heavy" level of smoking, 92.6\% in movies with "moderate" smoking, and $83.6 \%$ in movies with a "mild" level of smoking $\left(\chi^{2}=13.55\right.$, $\mathrm{df}=4, \mathrm{p}=0.009)$.

\section{Opinion of smoking in the movie}

The anti-smoking advertisement had a significant overall effect on opinion of smoking in the movie, with subjects significantly more likely to indicate that the smoking in the movie was "not OK", if they saw the anti-smoking ad before the movie $\left(\chi^{2}=82.95\right.$, df $\left.=2, p<0.0001\right)$. There was a highly significant relation between opinion of the smoking and smoking status of respondents $\left(\chi^{2}=24.08\right.$, df $=2$, $\mathrm{p}<0.0001)$, with smokers significantly more likely to approve of the smoking in the movie. The effect of the intervention on approval was analysed separately for smokers and non-smokers.

Among non-smokers, table 3 shows there was a significant effect in favour of the intervention group, with $48.2 \%$ of the intervention group saying that the smoking was "not OK", compared with $25.2 \%$ of the control group $\left(\chi^{2}=83.11\right.$, $\mathrm{df}=3, \mathrm{p}<0.0001)$. A binary logistic regression was carried out to adjust for age and movie exposure differences, which indicated there were significantly more non-smoking intervention respondents who said that the smoking in the movie was "not OK", compared with non-smoking control respondents (Wald $\chi^{2}=75.784$, df $=1, \mathrm{p}<0.0001$ ).

Among smokers, there was no difference between groups in relation to the level of approval of smoking in the movie $\left(\chi^{2}=2.52, \mathrm{df}=2, \mathrm{p}=0.28\right)$, although the intervention group showed a higher percentage of disapproval than the control group (table 3). After adjusting for age and movie, there was still no significant difference between smokers' level of approval (Wald $\chi^{2}=1.37, \mathrm{df}=1, \mathrm{p}=0.242$ ).

\section{Intention to smoke}

There was no overall significant effect of the intervention on intention to smoke $\left(\chi^{2}=3.26, \mathrm{df}=2, \mathrm{p}=0.196\right)$. There was a significant relation between intention to smoke and smoking status $\left(\chi^{2}=643.09, \mathrm{df}=2, \mathrm{p}<0.0001\right)$, with a lower percentage of smokers than non-smokers indicating they would be unlikely to be smoking this time next year. Therefore, a separate analysis for smokers and non-smokers for the effect of the intervention on intention to smoke was undertaken. The anti-smoking advertisement had a significant effect on intention to smoke for respondents who were current smokers $\left(\chi^{2}=9.03, \mathrm{df}=2, \mathrm{p}=0.01\right)$. After adjusting for age and movie, there was a significantly higher percentage of current smokers who said they were unlikely to be smoking this time next year in the intervention group than the control group (Wald $\chi^{2}=4.59, \mathrm{df}=1, \mathrm{p}=0.03$ ) (table 4).

However, there was no difference between groups in smoking intentions among non-smokers in bivariate analyses $\left(\chi^{2}=0.97, \mathrm{df}=2, \mathrm{p}=0.62\right)$ or binomial regression after adjusting for age and movie (Wald $\chi^{2}=1.25$, df $=1$, $\mathrm{p}=0.263$ ) (table 4).

\section{DISCUSSION}

The study provided some support for the hypothesis that when an anti-smoking advertisement is shown before a movie with smoking, the smoking in the movie is less likely to be perceived as justified, although this finding was only observed among non-smokers. This finding adds strength to Pechmann and Shih's 1999 findings ${ }^{18}$ that ninth grade students who saw an anti-smoking advertisement tended to elicit negative thoughts about smoking and smokers. There is strong evidence that youth's perceptions of smokers are highly predictive of their smoking behaviours. ${ }^{33-35}$

The study supported the second hypothesis for smokers (but not non-smokers) that an anti-smoking advertisement shown before a movie with smoking scenes would result in lower intentions to smoke in the future. The finding that a higher proportion of smokers in the intervention condition reported they were unlikely to be smoking in the future suggests that the anti-smoking advertisement may have encouraged young smokers to consider quitting, at least in

Table 4 Intention to smoke among smokers and non-smokers, by condition

\begin{tabular}{llllll}
\hline & \multicolumn{2}{l}{ Non-smokers } & & \multicolumn{2}{l}{ Smokers } \\
\cline { 2 - 3 } \cline { 5 - 5 } \cline { 5 - 5 } & Control $\mathbf{n = 7 2 8}$ & Intervention $\mathbf{n = 1 1 1 2}$ & & Control $\mathbf{n = 7 2}$ & Intervention $\mathbf{n = 1 1 3}$ \\
\hline Unlikely to be smoking & $95.1 \%$ & $95.4 \%$ & $31.9 \%$ & $47.8 \%$ \\
Can't decide how likely & $4.3 \%$ & $3.6 \%$ & $22.2 \%$ & $27.4 \%$ \\
Likely to be smoking & $0.7 \%$ & $1.0 \%$ & $45.8 \%$ & $24.8 \%$ \\
\hline
\end{tabular}


the short term. The strength of the effect was relatively large (47.8\% of intervention smokers compared with $31.9 \%$ of controls), given the intervention comprised only one, 30 second advertisement. Pechmann and Shih ${ }^{18}$ showed that without the presence of an anti-smoking advertisement movie viewers intention to smoke was enhanced by movies with smoking content. Screening the anti-smoking advertisement neutralised the effect of the smoking on intention to smoke in the Pechmann study, as suggested in our own study.

It is worth noting that $95 \%$ of non-smokers in both the control and intervention groups said they did not intend to be smoking in the future, so there was very little room for improvement in this group. Australian and US research has found that stated intention among non-smokers to become smokers is a good predictor of smoking uptake. ${ }^{36-38}$ While the intervention did not appear to promote reduced intentions among non-smokers, there was no evidence that the intervention had the unintended effect of enhancing smoking intentions among teen non-smokers.

Recall of the anti-smoking advertisement among intervention subjects varied according to the amount of smoking in the movie and whether there was a competing health message being advertised at the same time as the antismoking advertisement. At best, $89.5 \%$ recalled the advertisement when there was no competing health advertisement and a moderate amount of smoking in the movie. At worst, $56.5 \%$ recalled the advertisement when the movie had a mild amount of smoking and a competing anti-alcohol advertisement. Given that in all cases there were at least four other advertisements of some type running before the antismoking advertisement and that the respondents had only seen one screening of the 30 second anti-smoking advertisement, these results were quite pleasing. They also have important ramifications for the placement of future antismoking advertisements in cinemas. Placing the advertisements before movies with moderate or heavy smoking content and avoiding competing health advertisements are key strategies for optimising recall of the advertisement.

Recall of characters smoking in the movie was unrelated to seeing the anti-smoking advertisement before the movie. The results indicate that the vast majority of cinemagoers remember who was smoking in the movies they see, even when there is little smoking content in those movies. Every respondent who saw the movie with heavy smoking content correctly recalled at least one character who smoked in that particular movie. The anti-smoking advertisement cannot be accused of drawing attention to the smoking in the movie, because young people recall the smoking in any case. However, this study suggests that anti-smoking ads can counter young non-smokers' perceptions of the smoking content as justified. This is a strong argument for using antismoking advertisements to counter the influence of smoking in movies.

The study design had two major limitations. Firstly, because the study was conducted in real movie theatres, it was not possible to randomly allocate movie goers to control or intervention groups. However, variables that significantly differed between control and intervention groups were identified and multivariate analyses were used to adjust for these differences. Furthermore, analyses were stratified by smoking status.

Secondly, we did not collect baseline information on approval of movie smoking or intention to smoke. In this study, it was judged that collection of this data would prime subjects (especially control group subjects) to smoking in movies. Additionally, matching of baseline and post-movie questionnaires in this setting would have been extremely difficult.

\section{What this paper adds}

Out of the Smokescreen is the first study that measures the impact of an anti-smoking ad in the "real world" of the cinema using a control group. Previous research by Pechmann and Shih (1999) suggested that anti-smoking ads screened before movies that portrayed characters smoking would "immunise" young people against positive smoking images in movies. Pechmann's study was carried out in a classroom context, and Pechmann and Shih identified the need to test the hypothesis in cinemas with current movies and real cinemagoers. Our study supports Pechmann's findings and provides much needed evidence that anti-smoking ads can not only change the way cinemagoers view smoking in movies but can also affect their intention to smoke.

Thirdly, the opportunistic nature of the sample raises the issue of representativeness. The study attempted to survey every young woman leaving the selected movies who appeared to be between 12 and 17 years of age, but there is no way of identifying or describing those cinemagoers who may have been missed. However, the free lipgloss proved to be quite an enticement and very few young cinemagoers who were approached, declined to complete the survey. Australian research $^{16}$ indicates that $94 \%$ of young Australians had attended the cinema in the last 12 months and 56\% had attended in the last four weeks. A school holiday period was chosen to optimise the likelihood of attaining a large representative sample of young cinemagoers.

The major strength of this study lies in the fact that it measured the reactions of the target audience to antismoking advertisements viewed under naturalistic conditions in real cinemas using a control group. An extensive literature search and consultation with anti-tobacco experts in Australia and the USA has produced no evidence that this type of study has been done previously. Pechmann and Shih ${ }^{18}$ acknowledge the limitations of conducting their research in "relatively sterile classroom settings". The findings of this "real life" study confirm Pechmann's findings that antismoking advertising before movies in which characters are smoking can have a discernible impact on attitudes to smoking and intention to smoke. Placing an anti-smoking advertisement before movies that contain smoking scenes can help to "immunise" young women against the influences of film stars smoking.

\section{ACKNOWLEDGEMENTS}

This project was funded by the NSW Health Women's Health Strategy. The authors acknowledge the support of the Australian National Tobacco Campaign and the staff of the Central Coast, Central Sydney and Macquarie Health Promotion Units.

\section{Authors' affiliations \\ C A Edwards, W C Harris, D R Cook, K F Bedford, Y Zuo, Health \\ Promotion, Central Coast and Central Sydney, NSW, Australia}

\section{REFERENCES}

1 Lawson V. Glamour Puff. Tobacco Control 2003;12:3-5.

2 Carter Stacy. Worshipping at the Alpine Altar: promoting tobacco in a world without advertising. Tobacco Control 2001;10:391-3.

3 Amos A, Hagland M. From social taboo to "torch of freedom": the marketing of cigarettes to women. Tobacco Control 2000;9:3-8.

4 Mekemson C, Glantz S. How the tobacco industry built its relationship with Hollywood. Tobacco Control 2002;11(suppl I):i81-91.

5 Sargent JD, Tickle JJ, Beach ML, et al. Brand appearances in contemporary cinema films and contribution to global marketing of cigarettes. Lancet 2001;357:29-32. 
6 Gibson B, Maurer J. Cigarette smoking in the movies: The influence of product placement on attitudes toward smoking and smokers. J Applied Social Psychol 2000;30:1457-1483

7 Hazan AR, Lipton HL, Glantz S. Popular film do not reflect current tobacco use. Am J Public Health 1994;84:998-1000.

8 Eaton L. Tobacco companies exploit women says WHO. BMJ 2001;322:1384.

9 Escamilla G, Cradock AL, Kawachi I. Women and smoking in Hollywood movies: a content analysis. Am J Public Health 2000;90:412-14.

10 Mclntosh WD, Bazzini DG, Smith SM, et al. Who smokes in Hollywood? Characteristics of smokers in popular films from 1940 to 1989. Addict Behav 1998;23:395-8.

11 Dalton M, Tickle JJ, Sargent JD, et al. The incidence and context of tobacco use in popular movies from 1988 1997. Prev Med 2002;34:516-23.

12 Tickle JJ, Sargent JD, Dalton MA, et al. Favourite movie stars, their tobacco use in contemporary movies, and its association with adolescent smoking. Tobacco Control 2001;10:16-22.

13 Sargent JD, Dalton MA, Beach ML, et al. Viewing tobacco use in movies: does it shape attitudes that mediate adolescent smoking? Am J Prev Med 2002;22:137-45.

14 Distefan JM, Gilpin EA, Sargent JD, et al. Do movie stars encourage adolescents to start smoking? Evidence from California. Prev Med 1999;28:1-11.

15 Dalton $M$, Sargent JD, Beach ML, et al. Effect of viewing smoking in movies on adolescent smoking inititiation: a cohort study. Lancet 2003; published online June 10.

16 Anon. Cinema in Australia. Roy Morgan Research, 1999.

17 Anon. Cinema-the Multicultural Audience. AC Nielsen, 1999.

18 Pechmann C, Shih C. Smoking scenes in movies and anti-smoking advertisements before movies: effects on youth. Journal of Marketing 1999;63:1-13

19 James $\mathbf{R}$, Leivers $S$, Hannaby L, et al. Using cinema advertising to promote health. Health Promotion Journal of Australia 1996;6:53-4.

20 Fishbein M, Ajzen I. Beliefs, attitudes, intentions, and behavour: an introduction to theory and research. Massachusetts: Addison-Wesley, 1975.

21 Glanz K, Lewis FM, Rimmer BK, eds. Health behaviour and health education: theory, research and practice. San Francisco: Jossey-Bass Publishers, 1990:68-9.
22 Petty RE, Cacioppo JT. Attitude change. central and peripheral routes to persuasion. Advances in experimental social psychology. New York: Springer-Verlag, 1986.

23 Hill D. Carroll T. Australia's National Tobacco Campaign. Tobacco Control 2003;12(suppl II):ii9.

24 White V, Tan N, Wakefield M, et al. Do adult focused anti-smoking campaigns have an impact on adolescents? The case of the Australian National Tobacco Campaign. Tobacco Control 2003;12(suppl II):ii23-9.

25 Wilding J6, Cook S. Sex differences and individual consistency in voice identification. Perceptual and Motor Skills 2000;91:535-8.

26 Yang Z, Wu H. Source monitoring differences between male and female students. Psychological Science (China) May 2000;23:329-31.

27 Anon. Screenit! Entertainment Review. www.screenit.com.

28 Bruckheimer B, Lowry H (Producers), Khouri C (Director). Divine Secrets of the Ya Ya Sisterhood [Motion Picture]. United States: Warner Bros, 2002.

29 Phillips D, Butterworth S(Producers), Butterworth J(Director). Birthday Girl [Motion Picture]. United States: Miramax, 2002.

30 Barnes NK (Producer), Wietz C, Wietz P(Directors). About a Boy [Motion Picture]. United States: Universal studios, 2002.

31 Ganis S (Producer), Brill S (Director). Mr Deeds [Motion Picture]. United States: Sony Pictures, 2002.

32 Parkes WF, MacDonald L (Producers), Sonnenfeld B (Director). Men in Black II [Motion Picture]. United States: Sony Pictures, 2002.

33 Barton J, Chassin L, Presson C, et al. Social image factors as motivators of smoking initiation in early and middle adolescence. Child Development 1982;53:1499-511

34 Chassin L, Presson C, Bensenberg $M$, et al. Predicting adolescents intention to smoke Cigarettes. J Health Social Behav 1981;22:445-55.

35 Norman N, Tedeschi J. Self presentation, reasoned action, and adolescents decision to smoke cigarettes. J Applied Social Psychol 1989;19:543-58.

36 US Department of Health and Human Services. The health benefits of smoking cessation. A report of the Surgeon General, 1990. Rockville, Maryland: Public Health Service, Centers for Disease Control, Office on Smoking and Health, 1990;(DHHS Publication No (CDC) 90-8416.)

37 Armstrong B, de Klerk N, Shean R, et al. Influence of education and advertising on the uptake of smoking by children. Med J Aust 1990;152:117-24.

38 Shean R, de Klerk N, Armstrong B, et al. Seven year follow-up of a smokingprevention program for children. Aust J Public Health 1994; 18:205-8.

\section{The lighter side}

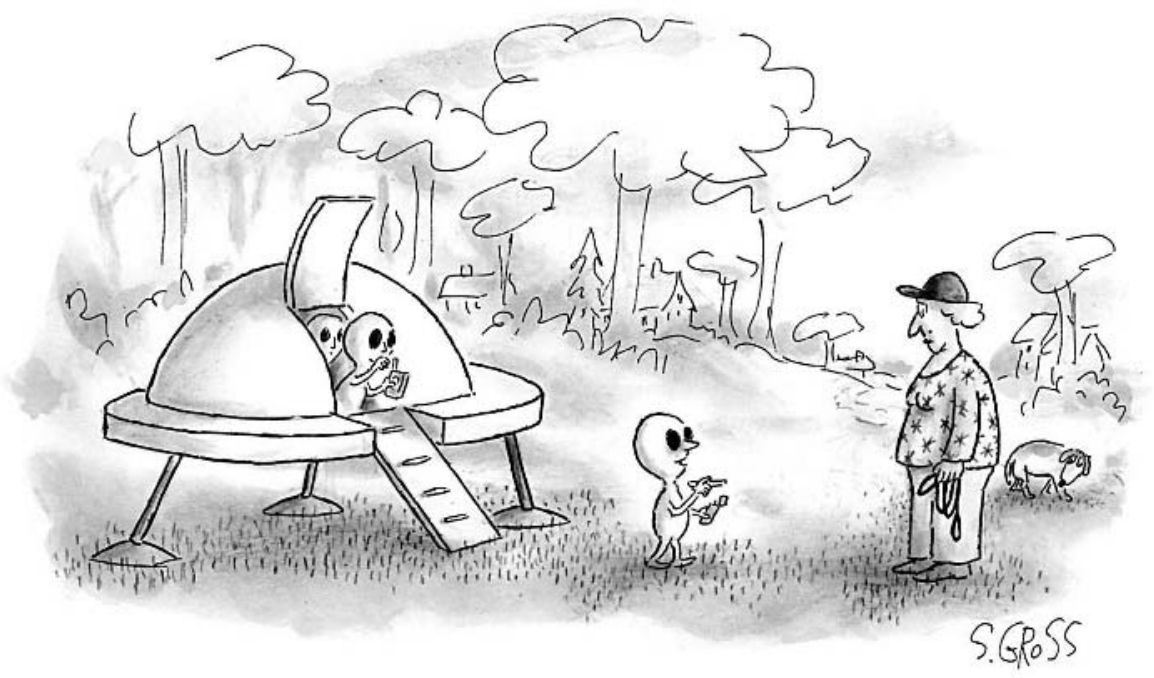

"We've come bere to smoke."

(c) The New Yorker Collection 2003. Sam Gross from cartoonbank.com. All rights reserved. 